\title{
Les prions : essor, décadence, renaissance
}

Au cours d'encéphalopathies dégénératives animales (tremblante du mouton et de la chèvre ou scrapie) et humaines (maladie de Creutzfeldt-Jakob, kuru) s'accumulent des particules protéiques dont le constituant principal a été appelé prion $(\operatorname{Pr} P)$. On a voulu attribuer à ces prions un rôle essentiel dans la genèse de ces maladies. Récemment, on a obtenu chez le hamster [1] et chez l'homme [2] un ADN complémentaire permettant de montrer que cette protéine est codée par un gène unique. Chez l'homme, la séquence protéique déduite compte 245 acides aminés et un poids moléculaire voisin de 27000 avant glycosylation. La protéine est présente dans l'organisme normal ; un ARN messager est retrouvé non seulement dans le système nerveux central mais aussi dans d'autres tissus et, en quantités égales, chez les animaux normaux et infectés. Le gène humain a pu être assigné au chromosome 20 , celui de la souris au chromosome 2 .

L'ensemble de ces résultats semblait éliminer les prions comme agent causal des nombreuses maladies neurologiques dans lesquelles on les avait impliqués, y compris la maladie d'Alzheimer. Mais à peine déboulonnés de leur piédestal, les prions viennent d'être remis en selle par l'équipe animée aux États-Unis par Prusiner. Ils ont montré d'abord que la protéine constituant les prions présente des différences selon qu'elle provient d'animaux nor-

importants résultats sont dus à une étude [4] combinant génétique et biologie moléculaire chez la souris, espèce mieux connue génétiquement que toute autre.

On connaissait la possibilité d'infecter des souris avec une préparation tirée du cerveau de souris atteintes. On savait également que dans la plupart des souches de souris, la durée d'incubation de la tremblante est de l'ordre de 100 jours. Une souche, I/LnJ, possède une durée d'incubation supérieure à 200 jours. $\mathrm{Si}$ on croise cette souche avec une autre (les auteurs ont choisi la souche NZW à durée d'incubation de 100 jours) tous les hybrides $F_{1}$ ont une durée d'incubation longue, caractère qui paraît donc dominant. Si l'on croise ces hybrides $F_{1}$ à nouveau avec des NZW (backcross) on obtient en nombre égal des souris à incubation courte (interprétées comme homozygotes NZW) et longue (interprétées comme hétérozygotes NZW/ I/LnJ). La durée d'incubation de la tremblante semble donc être sous l'influence d'un gène unique. Utilisant une sonde d'ADNc de hamster, les auteurs ont ensuite découvert un polymorphisme de restriction dans le gène de structure pour $\operatorname{PrP}$. On peut ainsi définir deux allèles $a$ et $b$. L'allèle $a$ est trouvé présent dans la souche NZW et une vingtaine d'autres dont six ont été testées et ont toutes une incubation courte. L'allèle $b$ est trouvé dans la souche I/LnJ et trois autres (dont la durée d'incubation n'est pas encore connue). A partir de ces données, une étude de liaison a été menée chez les souris ayant subi le backcross. La conclusion a été formelle : les souris à incubation courte sont homozygotes pour l'allèle $a$, celles à incubation longue sont hétérozygotes, portant à la fois $a$ et $b$. La durée d'incubation de la tremblante présente donc une liaison génétique avec les allèles du gène codant pour les prions. Les auteurs concluent à l'existence d'un complexe génétique formé par le gène dit Prni qui régit la durée d'incubation de la tremblante, et par le gène Prnp qui gouverne la protéine $\operatorname{PrP}$ ellemême. S'agit-il d'un seul et même gène ou de deux gènes étroitement liés? Il est impossible actuellement de trancher, mais le recours aux souris transgéniques permettra probablement de le faire. Le feuilleton des prions s'avère donc riche en rebondissements, et au rythme auquel travaillent les équipes, notamment celle de Californie, le prochain épisode ne. saurait tarder.

J.-C. D.

1. Basler K, Oesch B, Scott M et al. Scrapie and cellular PrP isoforns are encoded by the same chromosomal gene. Cell 1986; 46 : 417-28

2. Liao YCJ, Lebo RV, Clawson GA, Smuckler EA. Human prion protein cDNA : molecular cloning, chromosomal mapping, and biological implications. Science $1986 ; 233: 364-7$.

3. Meyer RK, McKinley MP, Bowman KA, Barry RA, Prusiner SB. Separation and properties of cellular and scrapie prion proteins. Proc Natl Acad Sci USA 1986 ; 83 : 2310-4.

4. Carlson GA, Kingsbury DT, Goodman PA et al. Linkage of prion protein and scrapie incubation time genes. Cell 1986 ; 46 : 503-11. 